ISSN : 2354 - 6034 (Print)

ISSN : 2599 - 0187 (Online)

\title{
ANALISIS LOYALITAS KONSUMEN PRODUK BERLABEL HALAL
}

\author{
Oleh : Nurul Izzah \\ Fakultas Ekonomi dan Bisnis Islam IAIN Padangsidimpuan \\ nurulizzahlubis@gmail.com
}

\begin{abstract}
This article aims to determine how much is the influence the product quality, brand image and halal label to consumer loyalty product of PT. Unilever Indonesia. The research method used is quantitative approach with multiple linear regression analysis. The research used primer and secondary data from consumer product of PT. Unilever Indonesia in Desa Hutaraja. The result of the research showed that there was the positif influence of product qualityand brand image variable to the consumer loyalty product of PT. Unilever Indonesia in Desa Hutaraja. The result of the research also showed that there was not influence of halal label variable to the consumer loyalty product of PT. Unilever Indonesia in Desa Hutaraja.
\end{abstract}

Keywords : Consumer Loyalty , Product Quality, Brand Image, Halal Label

\section{PENDAHULUAN}

Perkembangan ekonomi telah menuntut dunia industri untuk terus menghasilkan produk dengan inovasi terbaru. Tantangan ini untuk memenuhi permintaan konsumen yang juga terus berkembang.Barang konsumsi dikelompokkan menjadi empat jenis, yaitu barang yang sering dibeli (convenience goods), barang yang dibeli (shopping goods), barang yang mempunyai karakterisktik yang unik (specialty goods), dan barang yang belum dikenal (unsought goods). Produk yang banyak beredar di pasar termasuk kategori convenience goods. Produk yang mampu memberikan kejelasan kuantitas, isi, kualitas dan hal lain yang dianggap penting oleh konsumen cenderung akan memiliki konsumen dengan loyalitas yang tinggi.

Loyalitas konsumen terhadap suatu produk dipengaruhi oleh banyak hal. Diantaranya, kualitas produk, harga, desain, promosi, brand ambassador, dll. Konsumen akan memiliki loyalitas yang tinggi terhadap suatu produk jika produk tersebut berkualitas tinggi dengan kata lain produk tersebut mampu memberikan kepuasan yang diharapkan oleh konsumen. Faktor lain yang mempengaruhi loyalitas konsumen yaitu harga dan citra merek. Produk-produk dengan harga yang stabil serta citra merek yang baik juga cenderung lebih mudah menarik konsumen untuk terus melakukan pembelian yang berulang yang pada akhirnya terbentuk konsumen dengan loyalitas yang tinggi.

Indonesia sebagai negara dengan penduduk muslim terbesar berkewajiban menyediakan produk-produk yang memiliki jaminan kehalalan yang jelas. Konsumen berhak memperoleh informasi yang jelas tentang produk-produk yang 
akan dikonsumsinya. Islam mengajarkan agar seorang muslim mengkonsumsi produk-produk yang halalan thaiyiban. Produk-produk tersebut tidak mengandung unsur babi, bangkai, darah, alkohol dan tidak membahayakan kesehatan. Hal ini dijelaskan dalam Q.S Al-Maidah ayat 3.

"diharamkan bagimu (memakan) bangkai, darah, daging babi, (daging hewan) yang disembelih atas nama selain Allah, yang tercekik, yang terpukul, yang jatuh, yang ditanduk, ddan diterkam binatang buas, kecuali yang sempat kamu menyembelihnya, dan (diharamkan bagimu) yang disembelih untuk berhala..." (Q.S Al-Maidah ayat 3). ${ }^{1}$

Pemerintah memberikan wewenang kepada Departemen Kesehatan Republik Indonesia melalui LPPOM bekerjsama dengan Majelis Ulama Indonesi (MUI). Hal ini dilakukan untuk memberikan kejelasan informasi terkait kehalalan dan kesehatan produk-produk yang beredar kepada konsumen muslim di Indonesia. Melalui kerjasama ini, kejelasan kandungan produk dan labelisasi halal dapat dilakukan.

PT. Unilever Indonesia merupakan salah satu perusahaan yang memproduksi barang-barangconvenience goods. PT. Unilever Indonesia telah sejak lama memproduksi produk konsumen yang menjadi kebutuhan sehari-hari masyarakat. Produk-produk perusahaan ini telah merajai pasaran produk konsumsi di Indonesia dan memiliki konsumen dengan loyalitas yang tinggi.

Penelitian oleh I Wayan Plong Widian dan Tjok Gede Raka Sukawati menyatakan bahwa kualitas produk berpengaruh positif dan signifikan terhadap loyalitas konsumen pasta gigi Pepsodent di Denpasar. ${ }^{2}$ Penelitian NilaKasuma Dewi, dkk juga menyatakan bahwa citra merek berpengaruh signifikan terhadap loyalitas konsumen Vaseline Hand and Body Lotion di kota Padang. ${ }^{3}$

Produk-produk PT. Unilever Indonesia beberapa tahun belakangan ini telah tersertifikasi halal dari LPPOM-MUI. Produk tersebut termasuk kategori kosmetik diantaranya Pepsodent, Close Up, Citra, Lux, Lifebuoy, Dove (Soap Bar), Zwitzal (Soap), Camay Internasional Fragrance (Soap).

Banyaknya produk konsumsi convienence goods yang beredar di pasaran baik yang telah tersertifikasi halal maupun yang belum tersertifikasi halal tentumempengaruhi pola konsumsi masyarakat. Perusahaan yang mampu menyediakan produk dengan kejelasan informasi yang diharapkan konsumen dan kehalalan produk akan membuat konsumen memiliki loyalitas terhadap produkproduknya.

Penelitian ini mencoba melihat keterkaitan variabel kualitas produk, citra merek dan labelisasi halal sebagai variabel independen dan variabel loyalitas

${ }^{1}$ Departemen Agama Republik Indonesia, 2007. Al-Qur'an dan Terjemahnya Bogor : SYGMA, h. 256.

${ }^{2}$ I Wayan Plong Widian dan Tjok Gede Raka Sukawati, 2016.Pengaruh Kualitas Produk dan Citra Merek terhadap Loyalitas konsumen Pasta Gigi Pepsodent PT. Unilever, diakses dari http://ojs.unud.ac.id pada tanggal 02 Mei 2019 pukul 10.38 WIB.

${ }^{3}$ Nila Kasuma Dewi, dkk, 2012.Pengaruh Iklan, Citra Merek, dan Kepuasan Konsumen terhadap Loyalitas Konsumen dalam Menggunakan Vaseline Hand and Body Lotion di Kota Padang (Studi Kasus di PT. Unilever Cabang Padang), dalam jurnal Manajemen dan Kewirausahaan, Universitas Taman Siswa Padang, volume 3 No. 2 Mei 2012, h. 34. 
konsumen sebagai variabel dependen. Berdasarkan hal tersebut, tujuan penelitian ini adalah : Untuk mengetahui pengaruh kualitas produk, citra merek dan labelisasi halal terhadap loyalitas konsumen produk PT. Unilever Indonesia.

\section{TINJAUAN PUSTAKA}

\section{Loyalitas Konsumen}

Loyalitas pelanggan adalah kesetiaan konsumen untuk terus menggunakan produk yang sama dari suatu perusahaan. ${ }^{4}$ Loyalitas konsumen terbentuk jika suatu produk mampu memberikan kepuasaan yang tinggi kepada konsumen. Kepusaan yang didapatkan oleh konsumen akan mendorong konsumen untuk melakukan pembelianyang berulang terhadap produk tersebut. Pembelian berulang yang konsumen lakukan akan membentuk loyalitas yang tinggi terhadap suatu produk. Sebaliknya, produk yang tidak mampu memberikan kepuasaan yang tinggi sesuai dengan harapan konsumen maka konsumen akan memiliki loyalitas yang rendah dan cenderung untuk beralih ke merek lain.

Loyalitas konsumen dipengaruhi oleh banyak hal diantaranya kualitas produk, citra merek, hrg, dll. Menurut Dharmamesta, loyalitas konsumen dipengaruhi oleh kualitas produk dan promosi. ${ }^{5}$ Konsumen yang loyal akan mudah didapatkan jika perusahaan sangat memperhatikan kualitas produk, harga dan citra merek produk yang diproduksi. Produk yang berkualitas dan harga yang wajar menurut konsumen akan lebih mudah membentuk konsumen dengan loyalitas tinggi. Selain itu, kemampuan perusahaan dalam membuat citra merek yang baik dimata konsumen juga menentukan pembentukan konsumen yang loyal terhadap produk tersebut..

\section{Kualitas Produk}

Kualitas produk adalah suatu nilai dari produk atau jasa, dimana nilai produk atau jasa sesuai dengan apa yang diharapkan atau melebihi apa yang dharapkan sehingga produk atau jasa tersebut dapat memenuhi kebutuhan pemakainya. ${ }^{6}$ Suatu produk dikatakan berkualitas jika produk tersebut mampu memberikan kepuasan sepenuhnya kepada konsumen. Kualitas produk dapat dianalisis dengan menggunakan delapan dimensi yaitu : a) performance, b) features, c)reability, d) durability, e) aesthetics, f) perceived quality, g) service ability, h) fit and finish.

Konsumen dalam memenuhi kebutuhan hidupnya tentu sangat memperhatikan kualitas produk. Hal ini dilakukan agar produk yang dibeli dapat memberikan manfaat bagi pemenuhan kebutuhan hidupnya. Islam juga mendorong individu agar membelanakan hartanya untuk membeli barang-barang yang baik dan halal dalam memenuhi kebutuhan hidupnya. Sesuai dengan Surat Al- Maidah ayat 88.

${ }^{4}$ Swastha Basu, 2009. Azaz-azaz Marketing, Yogyakarta : Liberty, h.89.

${ }^{5}$ Dharmamesta, Basu Swasthu, 1999.Loyalitas Pelanggan : Sebuah kajian konseptual sebagai panduan bagi peneliti. Jurnal ekonomi dan bisnis Indonesia, Vol. 14 No. 3 Tahun 1999, h. 67.

${ }^{6}$ Philip Kotler dan Gary Amstrong. 2000.Pinsip-Prinsip Pemasaran, Jakarta : Erlangga, h. 143 . 
" dan makanlah makanan yang halal lagi baik dari apa yang Allah telah rezekikan kepadamu, dan bertaqwalah kepada Allah yang kamu beriman kepada-Nya.” (Q.S. Al-Maidah : 88). ${ }^{7}$

\section{Citra Merek}

Menurut Kotler dan Keller, citra merek adalah suatu kesan yang ada di dalam benak konsumen mengenai suatu merek yang hal ini dibentuk oleh pesan dan pengalaman konsumen mengeni merek sehingga menimbulkan citra yang ada dalam benak konsumen. ${ }^{8}$ Citra merek juga didefenisikan sebagai deskripsi tentang asosiasi dan keyakinan konsumen terhadap merek tertentu. Citra merek dapat dibentuk dengan berbagai informasi dan pengalaman konsumen terhadap suatu produk. Citra merek dapat positif atau negatif, tergantung kepada sikap konsumen terhadap merek. Konsumen yang memiliki citra merek positif terhadap suatu produk akan cenderung melakukan pembelian produk tersebut. ${ }^{9}$

Citra merek dibentuk oleh banyak faktor, diantaranya sebagai berikut:

1) Kualitas atau mutu, berkaitan dengan kualitas produk yang ditawarkan oleh produsen dengan merek tertentu.

2) Dapat dipercaya atau diandalkan, berkaitan dengan pendapat atau kesepakatan yang dibentuk oleh masyarakat tentang suatu produk yang dikonsumsi.

3) Kegunaan atau manfaat, yang berkaitan dengan fungsi dari suatu produk yang dapat dimanfaatkan oleh konsumen.

4) Pelayanan, yang berkaitan dengan tugas produsen dalam melayani konsumennya.

5) Resiko, berkaitan dengan besar kecilnya akaibat atau untung dan rugi yang mungkin dialami oleh konsumen.

6) Harga, berkaitan dengan tinggi rendahnya atau banyak sedikitnya jumlah uang yang dikeluarkan konsumen untuk memperoleh produk.

7) Citra yang dimiliki oleh merek itu sendiri, berupa pandangan, kesepakatan dan informasi yang berkaitan dengan suatu merek dari produk tertentu. ${ }^{10}$

\section{Labelisasi Halal}

Label merupakan sejumlah keterangan yang tercantum pada kemasan produk. Label minimal memuat tentang nama atau produk merek, bahna baku, bahan tambahan komposisi, informasi gizi, tanggal kadaluwarsa dan isi produk. Peraturan pelabelan produk pangan di Indonesia diatur dalam Peraturan Pemerintah Republik Indonesia No. 69 Tahun 1999. Peraturan tentang label dan periklanan makanan ini mengatur tata cara pelabelan serta ketentuan-ketentuan yang menyertainya.

Fungsi label menurut Kotler sebagai berikut :

${ }^{7}$ Departemen Agama Republik Indonesia, 2007. Al-Qur'an dan Terjemahnya Bogor : SYGMA, h. 298.

${ }^{8}$ Philip Kotler dan Kevin Lane Keller, 2009.Manajemen Pemasaran Edisi 13, Jakarta : PT. Indeks, h. 157.

${ }^{9}$ Fandy Tjiptono, 2011. Pemasaran Jasa, Yogyakarta :Andi, h.56.

${ }^{10}$ G. Leon, Schiffman dan Lazar L Kanuk. 2008. Perilaku Konsumen. Edisi Ketujuh, h. 124 . 
1) Label mengindentifikasi produk atau merek

2) Label menentukan kelas produk

3) Label menggambarkan beberapa hal mengenai produk (siapa pembuatnya, dimana dibuat, kapan dibuat, apa isinya, bagaimana menggunakannya, dan bagimana menggunakan secara aman)

4) Label mempromosikan produk lewat aneka gambar yang menarik. ${ }^{11}$

Halal dapat didefenisikan hal-hal yang boleh dan dapat dilakukan karena bebas atau tidak terikat dengn ketentuan-ketentuan yang melarangnya. Halal menurut Departemen Agama yang dimuat dalam KEPMENAG RI No. 518 Tahun 2001 tentang pemeriksaan dan Penetapan Pangan Halal adalah “...tidak mengandung unsur atau bahan haram atau dilarang untuk dikonsumsi umat Islam, dan pengolahannya tidak bertentangan dengan syariat Islam". ${ }^{12}$

Labelisasi halal adalah pencantuman tulisan halal pada kemasan produk yang menunjukkan bahwa produk tersebut berstatus produk halal.Di Indonesia, secara teknis sertifikasai halal ditangani oleh Lembaga Pengkajian Pangan Obatobatan dan Kosmetika (LPPOM) bekerja sama dengan Majelis Ulama Indonesia (MUI). Labelisasi halal diatur dalam Undang-Undang Republik Indonesia No. 33 Tahun 2014 tentang Jaminan Produk Halal. Di Indonesia, sertifikasi halal berlaku selama 2 tahun dan diperbaharui sesuai dengan perundang-undangan, pengawasannya dilakukan oleh lembaga pemeriksa halal. Jika dalam pemeriksaan ditemukan pelanggaran maka lembaga pemeriksa halal berhak untuk mencabut sertifikat halal yang telah dimiliki sebelumnya.

\section{METODE PENELITIAN}

Populasi penelitian ini adalahmasyarakat Desa Hutaraja Kecamatan Siabu, Kabupaten Mandailing Natal yang menjadi konsumen produk PT. Unilever Indonesia.Penelitian ini menggunakan simple random samplingyang merupakan bagian dari probability sampling dimana teknik pengambilan sampel ini memberikan peluang yang sama bagi setiap anggota populasi untuk dipilih menjadi anggota sampel. ${ }^{13}$ Untuk menentukan jumlah sampeldihitung dengan rumus slovin yaitu :

Dimana :

$$
n=\frac{\mathrm{N}}{1+\mathrm{Ne}^{2}}
$$

n : Jumlah sampel

N : Jumlah Populasi

e $\quad$ : Batas toleransi kesalahan (error tolerance)

Dalam penelitin ini, batas tolerasi kesalahan 10\%. Maka jumlah total sampel sebanyak 100 responden ynag merupakan konsumen produk PT. Unilever Indonesia.

${ }^{11}$ Philip Kotler dan Gary Amstrong., h.167.

${ }^{12}$ Sujana dan Eri Agustian H, 2013. Pengaruh Labelisasi Halal Terhadap Keputusan Pembelian Konsumen: Studi kasus pada produk Walls's Conello, dalam Jurnal Ilmih Manajemen Kesatuan, Sekolah Tinggi Ilmu Ekonomi Kesatuan Bogor, volume 1 No.2 2013, h. 46.

${ }^{13}$ Sugiono, 2009.Metode Penelitian Bisnis (Pendekatan Kuantitatif, Kualitatif dan H\&R), Bandung : CV Alfabet Bandung, h. 56. 
Data yang digunakan dalam penelitian ini terdiri dari data primer dan data sekunder. Teknik analisis data penelitian ini yaitu regresi linier berganda. Formula yang digunakan sebagai berikut.

$\mathrm{Y}=\beta_{0}+\beta_{1} \mathrm{X} 1+\beta_{2} \mathrm{X} 2+\beta_{3} \mathrm{X} 3+\mathrm{e}$

Dimana :

$$
\begin{array}{ll}
\mathrm{Y} & =\text { Loyalitas Konsumen } \\
\mathrm{X} 1 & =\text { Kualitas Produk } \\
\mathrm{X} 2 & =\text { Citra Merek } \\
\mathrm{X} 3 & =\text { Labelisasi Halal } \\
\beta_{0} & =\text { Konstanta } \\
\beta_{1}, \beta_{2} & =\text { Koefisien } \\
\mathrm{e} & =\text { error term }
\end{array}
$$

\section{HASIL PENELITIAN DAN PEMBAHASAN}

\begin{tabular}{|c|c|c|c|c|c|c|c|}
\hline \multirow[t]{2}{*}{ Model } & $\begin{array}{c}\text { Unstanda } \\
\text { rdized } \\
\text { Coefficie } \\
\text { nts } \\
\end{array}$ & $\begin{array}{l}\text { Std. } \\
\text { Error }\end{array}$ & $\begin{array}{l}\text { Standardi } \\
\text { zed } \\
\text { Coefficie } \\
\text { nts } \\
\end{array}$ & \multirow[t]{2}{*}{$\mathrm{T}$} & \multirow[t]{2}{*}{ Sig. } & $\begin{array}{l}\text { Collinear } \\
\text { ity } \\
\text { Statistics }\end{array}$ & \multirow[t]{2}{*}{ VIF } \\
\hline & B & & Beta & & & $\begin{array}{l}\text { Toleranc } \\
\mathrm{e}\end{array}$ & \\
\hline $\begin{array}{l}\text { (Constan } \\
\text { t) }\end{array}$ & 43.446 & 7.239 & & 4.270 & .002 & & \\
\hline X1 & .357 & .105 & .332 & 3.434 & .019 & .983 & 1.017 \\
\hline $\mathrm{X} 2$ & .171 & .126 & .195 & 1.555 & .016 & .983 & 1.017 \\
\hline X3 & .211 & .116 & .185 & 1.755 & .182 & .983 & 1.017 \\
\hline
\end{tabular}

Hasil Estimasi

Estimasi model dilakukan untuk melihat pengaruh variabel kualitas produk, harga dan labelisasi halal terhadap konsumen produk PT. Unilever Indonesia. Metode yang digunakan yaitu regresi linier berganda. hasil estimsi data yang dilakukan sebagai berikut.

Tabel 1. Hasil Estimasi

Sumber : Data Penelitian, diolah.

Berdasarkan Tabel 1. diatas maka persamaan analisis regresi linier berganda penelitian ini sebagai berikut.

$$
\begin{aligned}
& \mathrm{Y}=\beta_{0}+\beta_{1} \mathrm{X} 1+\beta_{2} \mathrm{X} 2+\beta_{3} \mathrm{X} 3+\mathrm{e} \\
& \mathrm{Y}=43,446+0,357 \mathrm{X} 1-0,171 \mathrm{X} 2+0,211 \mathrm{X} 3+7,239
\end{aligned}
$$

\section{Pengujian Hipotesis}

Uji t

Pengaruh parsial variabel-variabel independen terhadap variabel dependen dapat dilakukan dengan uji t. Derajat signifikansi yang digunakan dalam penelitian ini adalah $\alpha=0.10, \mathrm{df}=96$ (1.985) untuk membandingkan nilai t-tabel dengan nilai t-statistik. Hasil uji t dapat dilihat pada tabel dibawah ini.

Tabel 2 : Hasil Uji t-statistik

\begin{tabular}{lllll}
\hline Variabel & t-statistik & t-tabel & Prob. & Kesimpulan \\
\hline
\end{tabular}




\begin{tabular}{lllll}
\hline Kualitas Produk & 2.434 & 1.985 & 0.019 & Signifikan \\
\hline Citra Merek & 2.355 & 1.985 & 0.082 & Signifikan \\
\hline Labelisasi Halal & 1.256 & 1.985 & 1.106 & Tidak Signifikan \\
\hline
\end{tabular}

Sumber : Data Penelitian, diolah

Berdasarkan Tabel 2. diatas diketahui bahwa nilai t-statistik variabel kualitas produk lebih besar dibandingkan dengan nilai t-tabel atau 2,434 $>1,985$. Hal ini berarti bahwa kualitas produk berpengaruh signifikan secara parsial terhadap loyalitas konsumen produk PT. Unilever Indonesia. Variabel citra merekmemiliki nilai t-statistik yang lebih kecil dibandingkan dengan nilai t-tabel atau 2,355<1,985. Hasil ini berarti bahwa citra merek tidak signifikan berpengaruh terhadap loyalitas konsumen produk PT. Unilever Indonesia. Sedangkan variabel labelisasi halal memiliki nilai t-statistik yang lebih kecil dibandingkan dengan nilai t-tabel atau $1,256<1,985$. Hasil ini berarti bahwa labelisasi halal tidak signifikan berpengaruh terhadap loyalitas konsumen produk PT. Unilever Indonesia.

\section{Uji F}

Uji F digunakan untuk mengetahui pengaruh variabel independen secara simultan terhadap variabel dependen. Nilai F statistik sebesar 4,380 dan nilai $F$ tabel sebesar 2,699 dengan nilai df $(3,96)$. Nilai $F$ statistik lebih besar dibandingkan dengan nilai $\mathrm{F}$ tabel atau 4,380 $>2,699$. Dengan demikian dapat disimpulkan bahwa kualitas produk, citra merek dan labelisasi halalsecara bersama-sama berpengaruh terhadap loyalitas konsumen produk PT. Unilever Indonesia.

\section{Pembahasan}

Hasil estimasi menunjukkan bahwa variabel kualitas produk dan citra merekmemiliki hubungan yang positif dan signifikan terhadap loyalitas konsumen produk PT. Unilever Indonesia.Hubungan ini sesuai dengan hipotesis awal yang menyatakan bahwa kualitas produk dan citra merekmemiliki hubungan yang positif dengan loyalitas konsumen. Hal ini menunjukkan bahwa semakin baik kualitas, citra merek dan labelisasi halal produk-produk yang diproduksi oleh PT. Unilever Indonesia maka konsumen akan semakin loyal untuk menggunakan produk tersebut.

Menurut Dharmamesta, loyalitas konsumen dipengaruhi oleh kualitas produk dan promosi. ${ }^{14}$ Perusahaan yang sangat memperhatikan kualitas produk dan menawarkan harga yang sangat wajar akan lebih mudah mendapatkan konsumen yang loyal. Karena kualitas produk yang baik akan memberikan kepuasaan konsumen yang tinggi. Dengan demikian, produk yang mampu memberikan kepuasan kepada konsumen akan lebih mudah memperoleh konsumen yang memiliki loyalitas yang tinggi.

Labelisasi halaltidak berpengaruh signifikan terhadap loyalitas konsumen produk PT. Unilever Indonesia. Labelisasi halal pada produk-produk yang diproduksi PT. Unilever Indonesia belum signifikan mempengaruhi loyalitas konsumen di Desa Hutaraja. Hal ini disebabkan tingkat pengetahuan dan

${ }^{14}$ Dharmamesta, Basu Swasthu., h. 77. 
kesadaran konsumen di Desa Hutaraja tentang produk-produk yang telah terlabelisasi halal masih relatif rendah. Keputusan masyarakat di Desa Hutaraja dalam memilih produk untuk dikonsumsi masih didominasi oleh faktor selain labelisasi halal. Faktor tersebut diantaranya kualitas produk, citra merek dan bahkan faktor harga. Konsumen banyak yang menyatakan bahwa produk yang popular lebih mendominsi dalam pemilihan produk untuk dikonsumsi.

\section{Kesadaran Masyarakat Terhadap Produk Berlabel Halal Masih Rendah}

Pengetahuan dan tingkat kedasaran konsumen di Indonesia khususnya di Desa Hutaraja untuk mengkonsumsi produk-produk yang telah terlabelisasi halal masih rendah. Kesadaran masyarakat untuk mengonsumsi produk berlabel halal perlu ditingkatkan. Menurut Badan Standarisasi Nasional (BSN) saat ini, produk Indonesia yang tersertifikasi halal masih sekitar 20 persen. Kesadaran masyarakat yang meningkat untuk mengonsumsi produk berlabel halal diharapkan akan mendorong produsen dunia usaha untuk melakukan sertifikasi halal.

Islam mengajarkan setiap muslim agar senantiasa mengkonsumsi barangbarang yang baik dan halal. Sebagaimana firman Allah SWT dalam Q.S AlBaqarah : 168.

Artinya : "Hai sekalian manusia, makanlah yang baik lagi halal dari apa yang terdapat di bumi, dan janganlah kamu mengikuti langkah-langkah syaitan; karena sesungguhnya syaitan itu adalah musuh yang nyata bagimu" (Q.S Al-Baqarah : 168). ${ }^{15}$

\section{PENUTUP}

Kesimpulan

Berdasarkan hasil penelitian dan pembahasan diatas, maka dapat disimpulkan bahwa variabelkualitas produk dan citra merek berpengaruh positif dan signifikan secara parsial terhadap loyalitas konsumen produk PT. Unilever Indonesia di Desa Hutaraja. Sedangkan variabel labelisasi halaltidaksignifikanmempengaruhiloyalitas konsumen produk PT. Unilever Indonesia di Desa Hutaraja. Masyarakat Desa Hutaraja memiliki loyalitas yang tinggi terhadap produk-produk PT. Unilever Indonesia direfleksikan dengan sebagian besar masyarakat telah sejak lama menggunakan produk-produk tersebut.

\section{Saran}

Peningkatan loyalitas konsumen produk PT. Unilever Indonesia di Desa Hutaraja dapat dilakukan dengan beberapa cara yaitu : (1) Mempertahankan kualitas produk, (2) Meningkatkan pengetahuan dan kesadaran konsumen tentang konsumsi produk-produk yang telah terlabelisasi halal.

\footnotetext{
${ }^{15}$ Departemen Agama Republik Indonesia, 2007. Al-Qur'an dan Terjemahnya Bogor : SYGMA, h. 45.
} 


\section{DAFTAR PUSTAKA}

Aaker, D.A, 1991.Managing Brand Equity: Capitalizing on the value of a brand name, New York : Free Press.

Departemen Agama Republik Indonesia, 2007.Al-Qur'an dan Terjemahnya Bogor : SYGMA.

Dharmamesta, Basu Swasthu, 1999.Loyalitas Pelanggan : Sebuah kajian konseptual sebagai panduan bagi peneliti. Jurnal ekonomi dan bisnis Indonesia, Vol. 14 No. 3 Tahun 1999.

Fandy Tjiptono, 2011. Pemasaran Jasa, Yogyakarta :Andi.

Ghozali, Imam, 2001.Aplikasi Analisis Multivariate Dengan SPSS. Edisi kedua Semarang : Badan Penerbit Universitas Diponegoro.

I Wayan Plong Widian dan Tjok Gede Raka Sukawati, 2016.Pengaruh Kualitas Produk dan Citra Merek terhadap Loyalitas konsumen Pasta Gigi Pepsodent PT. Unilever, diakses dari http://ojs.unud.ac.id pada tanggal 02 Mei 2019 pukul 10.38 WIB.

Nila Kasuma Dewi, dkk, 2012.Pengaruh Iklan, Citra Merek, dan Kepuasan Konsumen terhadap Loyalitas Konsumen dalam Menggunakan Vaseline Hand and Body Lotion di Kota Padang (Studi Kasus di PT. Unilever Cabang Padang), dalam jurnal Manajemen dan Kewirausahaan, Universitas Taman Siswa Padang, volume 3 No. 2 Mei 2012.

Philip Kotler dan Gary Amstrong. 2000.Pinsip-Prinsip Pemasaran, Jakarta : Erlangga.

M. Sulaeman Jajuli, 2016. Ekonomi Islam Umar bin Khattab, Yogyakarta : Deepublish.

Philip Kotler dan Kevin Lane Keller, 2009.Manajemen Pemasaran Edisi 13, Jakarta : PT. Indeks.

Sujana dan Eri Agustian H, 2013. Pengaruh Labelisasi Halal Terhadap Keputusan Pembelian Konsumen: Studi kasus pada produk Walls's Conello, dalam Jurnal Ilmih Manajemen Kesatuan, Sekolah Tinggi Ilmu Ekonomi Kesatuan Bogor, volume 1 No.2 2013.

Sugiono, 2009.Metode Penelitian Bisnis (Pendekatan Kuantitatif, Kualitatif dan $H \& R)$, Bandung : CV Alfabet Bandung.

Swastha Basu, 2009. Azaz-azaz Marketing, Yogyakarta : Liberty. 